\title{
Renal Afferent Vessel
}

National Cancer Institute

\section{Source}

National Cancer Institute. Renal Afferent Vessel. NCI Thesaurus. Code C33454.

The blood vessels that supply the nephrons of the kidney with oxygenated blood. 